\title{
Proinflammatory Cytokines: Possible Accomplices for the Systemic Effects of Clostridioides difficile Toxin B
}

This article was published in the following Dove Press journal:

Journal of Inflammation Research

\author{
Katia Fettucciari (D) \\ Alessandro Fruganti $\mathbb{1 D}^{2}$ \\ Andrea Marchegiani (D) ${ }^{2}$ \\ Stefano Brancorsini (iD) \\ Pierfrancesco Marconi ${ }^{1}$ \\ Gabrio Bassotti (iD) 3,4 \\ 'Department of Experimental Medicine, \\ University of Perugia Medical School, \\ Perugia, Italy; ${ }^{2} \mathrm{~S}$ chool of Biosciences and \\ Veterinary Medicine, University of \\ Camerino, Macerata, Italy; \\ ${ }^{3}$ Gastroenterology, Hepatology \& \\ Digestive Endoscopy Section, \\ Department of Medicine, University of \\ Perugia Medical School, Perugia, Italy; \\ ${ }^{4}$ Gastroenterology \& Hepatology Unit, \\ Santa Maria della Misericordia Hospital, \\ Perugia, Italy
}

Correspondence: Katia Fettucciari Department of Experimental Medicine, University of Perugia Medical School,

Piazza Lucio Severi I, Edificio B IV Piano, Sant'Andrea delle Fratte, Perugia 06/32, Italy

Tel +39755858124

Email katia.fettucciari@unipg.it

\begin{abstract}
Clostridioides difficile infection (CDI) has a serious impact on the healthcare system, and most of its pathogenic effects are mainly due to the activity of toxins A and $\mathrm{B}$ (TcdA and TcdB, respectively). The molecular mechanisms of their cytotoxic activity are well known, especially in the colon, where the infection occurs and normally remains localized. However, the mechanisms causing toxic effects on various systemic organs (extraintestinal manifestations) with frequent lethal outcomes in some patients affected by CDI are still poorly understood. Few studies are available that demonstrate low serum levels of Tcds in both experimental animal models and patients with CDI. Until now, it has remained unclear how low levels of circulating Tcds could lead to serious toxic effects. On the basis of our previous in vitro studies, in which the proinflammatory cytokines TNFalpha and IFN-gamma strongly potentiated the toxic activity of low doses of TcdB, we hypothesize that the presence of both $\mathrm{TcdB}$ in the circulation and a systemic proinflammatory cytokine storm may be responsible for the selective severe effects of TcdB in some patients. This may occur in patients with severe CDI and systemic Tcds, in whom proinflammatory cytokines such as TNF-alpha and IFN-gamma reach a significant concentration in the circulation. This hypothesis could identify therapeutic interventions based on the reduction or neutralization of the indirect toxic action of these cytokines.
\end{abstract}

Keywords: Clostridioides difficile, toxin B, proinflammatory cytokines, TNF-alpha, IFNgamma, systemic effects

\section{Introduction}

Clostridioides $^{1}$ difficile infection (CDI) represents an important burden on the healthcare systems of both Eastern and Western populations ${ }^{2,3}$ as a major cause of iatrogenic diarrhoea, and it is increasingly present within the community. ${ }^{4}$ The clinical picture of CDI is mutable and mainly involves the gastrointestinal tract, varying from asymptomatic carrier status to life-threatening diarrhoea. ${ }^{5}$ However, the effects of CDI may sometimes become systemic with extraintestinal manifestations (liver, lung, kidney, cardiac, and neurological impairment) and multiorgan dysfunction syndrome with a clinical picture of toxaemia. ${ }^{6-15}$ Of interest, recurrent extraintestinal manifestations are also correlated with CDI relapse. $^{16}$

It is worth noting that to date, the mechanisms responsible for the systemic effects of CDI are poorly known, and data on this topic are relatively scarce. Here, we hypothesize that these effects may be due to a "systemic proinflammatory cytokine storm" occurring during CDI, which enhances the toxicity of C. difficile toxins (Tcds) once they reach the systemic circulation. 


\section{Pathophysiological Aspects of CDI}

The pathological effects of $C$. difficile are mainly due to the production of two large glucosylating toxins, toxin $\mathrm{A}(\mathrm{Tcd} \mathrm{A})$ and toxin $\mathrm{B}(\mathrm{TcdB}) .{ }^{17-20} \mathrm{Tcd} \mathrm{A}$ and TcdB inactivate Rho-GTPases by monoglucosylation, with the following effects:

(a) loss of the cytoskeletal structure, disassembly of focal adhesions and disruption of tight junctions ${ }^{17-21}$ (in cultured cells, these effects cause cell rounding (cytopathic effect); ${ }^{17-20}$

(b) arrest of the cell cycle, reduced expression of cyclins and activation of cyclin-dependent kinases involved in cell cycle phase progression; ${ }^{17-20,22}$

(c) cell death by apoptosis or necrosis (cytotoxic effect). ${ }^{17-20,22}$

In vivo, TcdA and $\mathrm{TcdB}$ disrupt epithelial tight junctions and induce cell death, causing direct injury to the colonic epithelium. Furthermore, Tcds stimulate colonic epithelial cells to release proinflammatory cytokines and neutrophil chemoattractants, which in turn lead to an acute inflammatory response, a key characteristic of the clinical picture of CDI. ${ }^{5,17-21}$ An impaired barrier within the context of active inflammation subsequently leads to enhanced intestinal and vascular permeability. Thus, the loss of a protective barrier favours the entry of Tcds and/or bacteria into the lamina propria, resulting in increased intestinal inflammation. ${ }^{17-21}$ The deepening of the lesion at the level of the submucosa could therefore favour the passage into the systemic circulation of Tcds.

TcdA primarily affects the intestinal epithelium, while TcdB has a broader cell tropism and represents the main virulence factor of $C$. difficile. ${ }^{19}$ There is evidence suggesting that Tcds can reach the circulation during CDI, causing systemic effects. ${ }^{6-15}$ In experimental animal models (mouse and guinea pig), the presence of circulating and quantifiable amounts of Tcds has been related to the systemic effects of CDI and found to be associated with fatal diseases. ${ }^{10-13,23}$ The presence of circulating Tcds has also been demonstrated in patients with CDI. ${ }^{6,8,24}$

Of the two Tcds produced by $C$. difficile, TcdB is probably mainly responsible for the systemic effects ${ }^{12,13,23}$ due to its toxicity, which is approximately 1000 times higher than that of TcdA. ${ }^{17-21}$ The mechanism by which Tcds reach the systemic circulation in some individuals with CDI is likely due to the important tissue damage that profoundly alters the barrier effect of the intestinal mucosa. ${ }^{10-13,25,26}$ Thus, when the two Tcds enter the circulation, cells of various organs may be damaged. In fact, in vitro cytotoxic studies have demonstrated that apart from causing the death of epithelial cells and colonic myofibroblasts, ${ }^{17-22,27-29}$ these Tcds target hepatocytes, ${ }^{30}$ cardiomyocytes, ${ }^{31}$ lung fibroblasts, ${ }^{32}$ immunocytes, ${ }^{17-22,33}$ enteric neurons, ${ }^{17-22,34-36}$ and enteric glial cells. ${ }^{22,37-39}$

In cell culture models, death induced by TcdA and TcdB occurs in a glucosylation-dependent or glucosylationindependent manner, mainly by apoptosis with caspasedependent or caspase-independent mechanisms. ${ }^{17-20,22,39}$ Apoptosis is induced by activation of the executioner caspases-3 and -7 , which can occur via a death receptordependent extrinsic or by a mitochondria-dependent intrinsic pathway. ${ }^{17-20,40,41}$ Apoptosis can also be activated in a caspase-independent manner by the cleavage and activation of pro-apoptotic Bcl-2 family proteins and non-caspase proteases such as cathepsins and calpains. ${ }^{17-20,42,43}$

\section{Cytokines: Possible Accomplices of Systemic Effects During CDI}

The inflammatory response to CDI is characterized by increased local and systemic levels of cytokines, ${ }^{17-21,44-48}$ some of which are associated with disease severity and prognosis. ${ }^{46-48}$ However, it is important to understand the relationship between circulating Tcds and proinflammatory cytokines in CDI.

Human studies have shown that increased serum concentrations of tumour necrosis factor-alpha (TNF- $\alpha$ ) are associated with poor prognosis in patients with $\mathrm{CDI},{ }^{48}$ and in experimental animal models, substances able to decrease proinflammatory cytokine levels exert a protective effect against CDI. ${ }^{49}$ However, the production of proinflammatory cytokines during severe CDI cannot be the sole cause of the relevant systemic effects found in only some patients, since their production is high in all subjects with severe CDI. ${ }^{45}$

Susceptibility to the toxic action of Tcds varies between different cell types, and the systemic concentrations of Tcds can be so low as to cause only marginal toxic effects; $3,10-13,22,50$ thus, we hypothesized that proinflammatory cytokines may strengthen the toxic effects of low doses of Tcds. This hypothesis stems from our recent in vitro studies in which TNF- $\alpha$ and interferon-gamma (IFN- $\gamma$ ) given before, concomitantly, or after low doses of TcdB $(0.1 \mathrm{ng} / \mathrm{mL}$ or $1 \mathrm{ng} / \mathrm{mL})$ strongly enhanced the apoptosis 
induced by TcdB in enteric glial cells. ${ }^{22,50}$ Apoptosis was characterized by an increase in caspase-3, caspase-7, caspase-9 and PARP activation without any change in the expression of Bcl-2 family members (Figure 1). ${ }^{22}$

\section{Discussion}

According to our hypothesis, two conditions must exist to have toxic systemic effects during CDI:

(a) The production of high levels of proinflammatory cytokines is necessary. ${ }^{17-21,44-48}$ In patients with severe CDI, the systemic inflammatory response (as documented in both patients and experimental animal models) ${ }^{6,10-13,48,51}$ is due to not only local tissue damage but also the inflammatory action of the Tcds, ${ }^{17-21,44-48,52}$ the structural and metabolic components released by $C$. difficile itself, and the modification of the intestinal microbial flora following C. difficile-specific therapy; ; $23-26,53-56^{-1}$

(b) Tcds have to reach the systemic circulation (a characteristic limited to only some patients with CDI). ${ }^{6-13}$
In these conditions, the interaction between TcdB, TNF- $\alpha$ and IFN- $\gamma$ can trigger an increase in the toxicity of TcdB and its systemic pathological effects (Figure 2). Of interest, this enhanced toxicity in vivo might occur at extremely low concentrations of Tcds, ${ }^{10}$ ones comparable to those that synergize in vitro with inflammatory cytokines to induce strong cell death. ${ }^{22}$ Since some evidence suggest that TcdA can also reach the circulation in patients with severe CDI and cause extraintestinal manifestations, ${ }^{6-16}$ it is of great interest to know if proinflammatory cytokines can increase its toxicity as it happens for TcdB and if the two effects can further amplify the systemic effects of CDI.

In conclusion, one of the pivotal mechanisms underlying the systemic effects of CDI could be the pathological alliance between $C$. difficile and proinflammatory cytokines. ${ }^{50}$ This relationship could promote investigations aimed at antagonizing this mechanism by the use of selective drugs targeting proinflammatory cytokines.

\section{Conclusions}

In conclusion, here, we hypothesize that when TcdB enters the systemic circulation of patients affected by severe CDI,

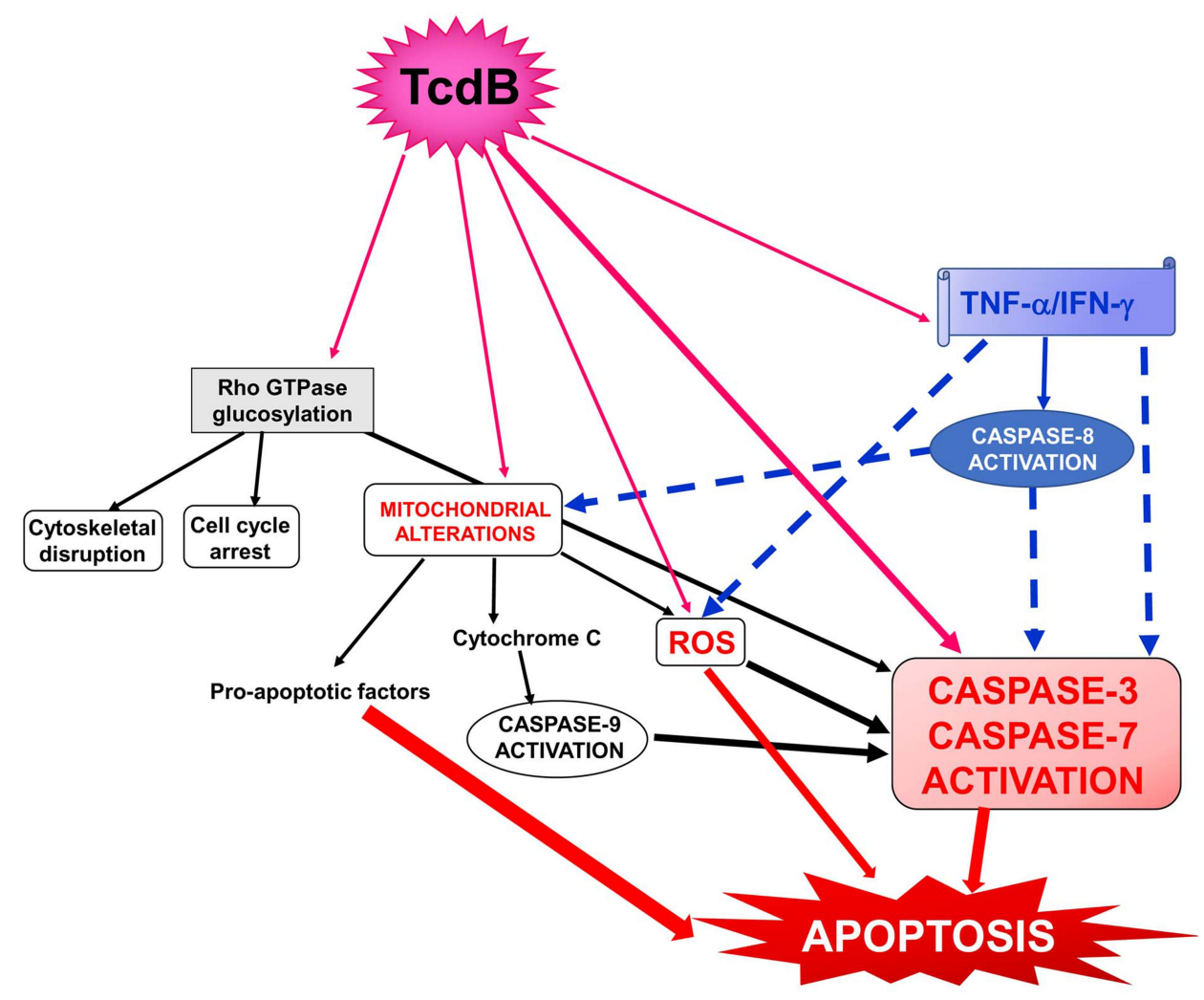

Figure I Schematic of the possible signalling pathways involved in the cytotoxic synergism between TcdB and the proinflammatory cytokines TNF- $\alpha$ and IFN- $\gamma$ in the induction of apoptosis. Full arrows indicate activation; dotted arrows indicate activation enhancement.

Abbreviations: TcdB, C. difficile toxin B; TNF- $\alpha$, tumour necrosis factor-alpha; IFN- $\gamma$, interferon-gamma; ROS, reactive oxygen species. 


\section{LOCALIZED GASTROINTESTINAL EFFECTS OF CDI}

\section{SYSTEMIC ORGAN DAMAGE BY CDI}

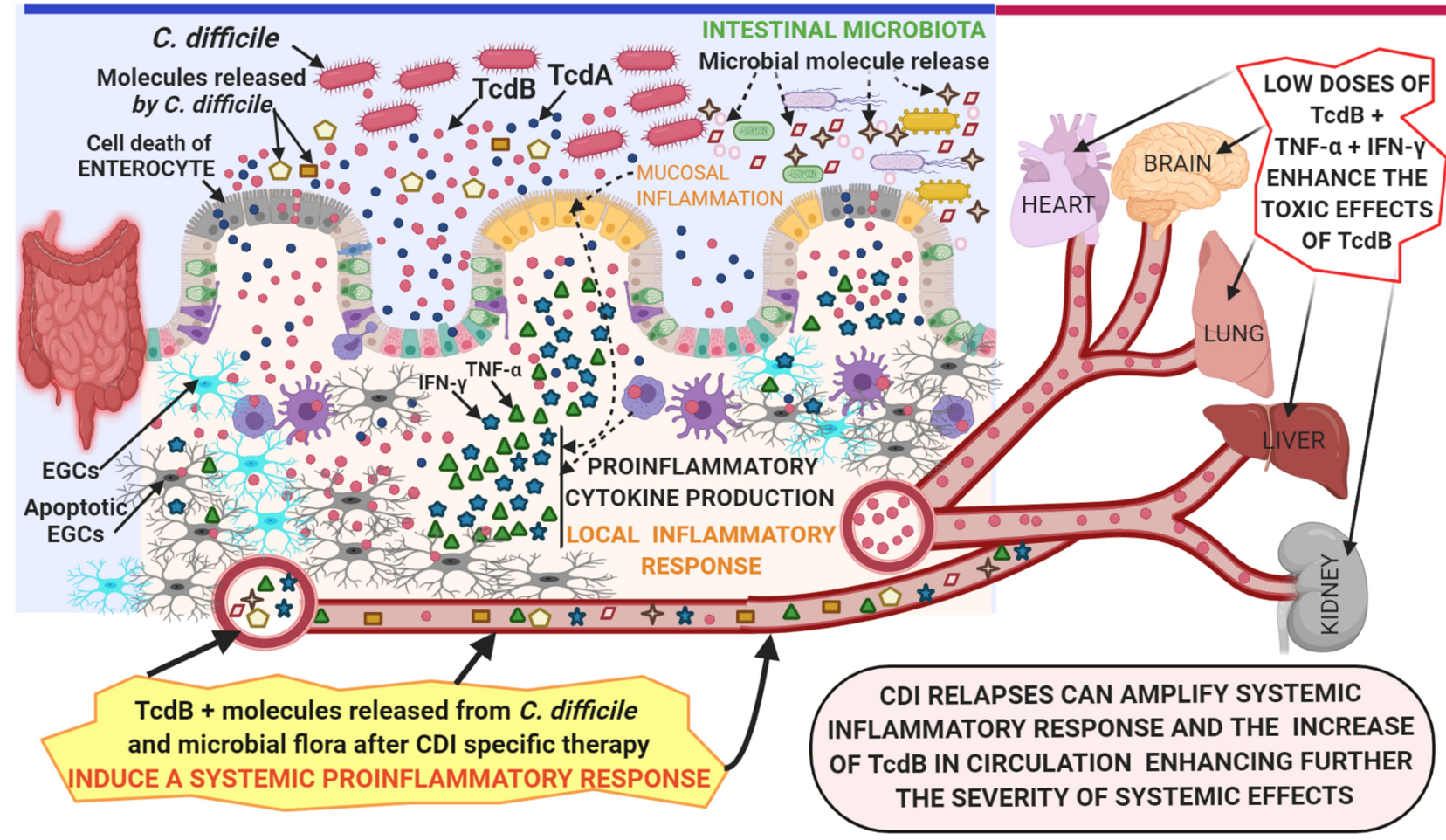

Figure 2 Proposed mechanism by which C. difficile toxins, in particular TcdB, enter the circulation and cause toxic effects enhanced by the systemic proinflammatory cytokines TNF- $\alpha$ and IFN- $\gamma$ on various systemic organs in severe CDI.

Notes: The figure was Created with BioRender.com and was Adapted from "Gut-Brain-Axis", by BioRender.com (2020). Retrieved from https://app.biorender.com/ biorender-templates.

Abbreviations: TcdB, C. difficile toxin B; TcdA, C. difficile toxin A; TNF- $\alpha$, tumour necrosis factor-alpha; IFN- $\gamma$, interferon-gamma; EGCs, enteric glial cells.

there can be a strong enhancement of its toxic action on various organs due to the presence of a systemic cytokine storm, in which proinflammatory cytokines such as TNF- $\alpha$ and IFN- $\gamma$ reach a significant concentration in the circulation. This hypothesis could highlight new therapeutic interventions based on the reduction or neutralization of the indirect toxic action of these cytokines.

\section{Abbreviations}

CDI, Clostridioides difficile infection; Tcds, C. difficile toxins; TcdA, C. difficile toxin A; TcdB, C. difficile toxin $\mathrm{B}$; TNF- $\alpha$, tumour necrosis factor-alpha; IFN- $\gamma$, interferongamma.

\section{Author Contributions}

All authors made a significant contribution to the work reported, whether that is in the conception, study design, execution, acquisition of data, analysis and interpretation, or in all these areas; took part in drafting, revising or critically reviewing the article; gave final approval of the version to be published; have agreed on the journal to which the article has been submitted; and agree to be accountable for all aspects of the work.

\section{Funding}

This study received no funding.

\section{Disclosure}

The authors report no conflicts of interest for this work.

\section{References}

1. Lawson PA, Citron DM, Tyrrell KL, Finegold SM. Reclassification of Clostridium difficile as Clostridioides difficile (Hall and O'Toole 1935) prévot 1938. Anaerobe. 2016;40:95-99. doi:10.1016/j.anaerobe. 2016.06.008

2. Malekzadegan Y, Halaji M, Hasannejad-Bibalan M, Jalalifar S, Fathi J, Ebrahim-Saraie HS. Burden of Clostridium (clostridioides) difficile infection among patients in western Asia: a systematic review and meta-analysis. Iran J Public Health. 2019;48(9):1589-1599. 
3. Marra AR, Perencevich EN, Nelson RE, et al. Incidence and outcomes associated with Clostridium difficile infections. JAMA Netw Open. 2020;3(1):e1917597. doi:10.1001/jamanetworkopen.2019.17597

4. Guery B, Galperine T, Barbut F. Clostridioides difficile: diagnosis and treatments. BMJ. 2019;366:14609. doi:10.1136/bmj.14609

5. Czepiel J, Dróżdż M, Pituch H, et al. Clostridium difficile infection: review. Eur J Clin Microbiol Infect Dis. 2019;38:1211-1221.

6. Qualman SJ, Petric M, Karmali MA, Smith CR, Hamilton SR. Clostridium difficile invasion and toxin circulation in fatal pediatric pseudomembranous colitis. Am J Clin Pathol. 1990;94(4):410-416. doi:10.1093/ajcp/94.4.410

7. Sensini A, Marroni M, Bassotti G, et al. Clostridium difficile-associated reactive arthritis in an HLA-B27 negative male. J Clin Gastroenterol. 1993;16(4):354-355. doi:10.1097/00004836199306000-00020

8. Jacobs A, Barnard K, Fishel R, Gradon JD. Extracolonic manifestations of Clostridium difficile infections. Presentation of 2 cases and review of the literature. Medicine (Baltimore). 2001;80(2):88-101. doi:10.1097/00005792-200103000-00002

9. Dobson G, Hickey C, Trinder J. Clostridium difficile colitis causing toxic megacolon, severe sepsis and multiple organ dysfunction syndrome. Intensive Care Med. 2003;29(6):1030. doi:10.1007/ s00134-003-1754-7

10. Steele J, Chen K, Sun X, et al. Systemic dissemination of Clostridium difficile toxins $\mathrm{A}$ and $\mathrm{B}$ is associated with severe, fatal disease in animal models. J Infect Dis. 2012;205(3):384-391. doi:10.1093/ infdis/jir748

11. Gupta A, Patel R, Baddour LM, Pardi DS, Khanna S. Extraintestinal Clostridium difficile infections: a single-center experience. Mayo Clin Proc. 2014;89(11):1525-1536. doi:10.1016/j.mayocp.2014.07. 012

12. Carter GP, Chakravorty A, Pham Nguyen TA, et al. Defining the roles of $\mathrm{Tcd} A$ and $\mathrm{TcdB}$ in localized gastrointestinal disease, systemic organ damage, and the host response during Clostridium difficile infections. mBio. 2015;6(3):e00551. doi:10.1128/mBio.00551-15

13. Di Bella S, Ascenzi P, Siarakas S, Petrosillo N, Di Masi A. Clostridium difficile toxins $\mathrm{A}$ and $\mathrm{B}$ : insights into pathogenic properties and extraintestinal effects. Toxins (Basel). 2016;8(5):E134 doi:10.3390/toxins 8050134

14. Cimolai N. Are Clostridium difficile toxins nephrotoxic? Med Hypotheses. 2019;126:4-8. doi:10.1016/j.mehy.2019.03.002

15. $\mathrm{Yu} \mathrm{H}$, Chen $\mathrm{K}$, Wu J, et al. Identification of toxemia in patients with Clostridium difficile infection. PLoS One. 2015;10(4):e0124235. doi:10.1371/journal.pone.0124235

16. Gardiner BJ, Thorpe CM, Pinkham NV, McDermott LA, Walk ST, Snydman DR. A repeat offender: recurrent extraintestinal Clostridium difficile infection following fecal microbiota transplantation. Anaerobe. 2018;51:68-72. doi:10.1016/j.anaerobe. 2018.04.007

17. Sun X, Savidge T, Feng H. The enterotoxicity of Clostridium difficile toxins. Toxins (Basel). 2010;2(7):1848-1880. doi:10.3390/toxins20 71848

18. Pruitt RN, Lacy DB. Toward a structural understanding of Clostridium difficile toxins A and B. Front Cell Infect Microbiol. 2012;2:28. doi:10.3389/fcimb.2012.00028

19. Chandrasekaran R, Lacy DB. The role of toxins in Clostridium difficile infection. FEMS Microbiol Rev. 2017;41:723-750.

20. Aktories K, Schwan C, Jank T. Clostridium difficile toxin biology. Annu Rev Microbiol. 2017;71(1):281-307. doi:10.1146/annurevmicro-090816-093458

21. Voth DE, Ballard JD. Clostridium difficile toxins: mechanism of action and role in disease. Clin Microbiol Rev. 2005;18(2):247-263. doi:10.1128/CMR.18.2.247-263.2005

22. Fettucciari K, Ponsini P, Gioè D, et al. Enteric glial cells are susceptible to Clostridium difficile toxin B. Cell Mol Life Sci. 2017;74 (8):1527-1551. doi:10.1007/s00018-016-2426-4
23. Awad MM, Johanesen PA, Carter GP, Rose E, Lyras D. Clostridium difficile virulence factors: insights into an anaerobic spore-forming pathogen. Gut Microbes. 2014;5(5):579-593. doi:10.4161/19490976. 2014.969632

24. Lee NY, Huang YT, Hsueh PR, Ko WC. Clostridium difficile bacteremia, Taiwan1. Emerg Infect Dis. 2010;16(8):1204-1210. doi:10.32 01/eid1608.100064

25. Smits WK, Lyras D, Lacy DB, Wilcox MH, Kuijper EJ. Clostridium difficile infection. Nat Rev Dis Primers. 2016;2:16020.

26. Dicks LMT, Mikkelsen LS, Brandsborg E, Marcotte H. Clostridium difficile, the difficult "Kloster" fuelled by antibiotics. Curr Microbiol. 2019;76(6):774-782. doi:10.1007/s00284-018-1543-8

27. Jafari NV, Allan E, Bajaj-Elliott M. Human intestinal epithelial response(s) to Clostridium difficile. Methods Mol Biol. 2010; 646:135-146.

28. Mullan N, Hughes KR, Mahida YR. Primary human colonic myofibroblasts are resistant to Clostridium difficile toxin A-induced, but not toxin b-induced, cell death. Infect Immun. 2011;79(4):1623-1630. doi:10.1128/IAI.00686-10

29. Brito GA, Fujji J, Carneiro-Filho BA, Lima AA, Obrig T, Guerrant RL. Mechanism of Clostridium difficile toxin A-induced apoptosis in T84 cells. J Infect Dis. 2002;186(10):1438-1447. doi: $10.1086 / 344729$

30. Grossmann EM, Longo WE, Kaminski DL, et al. Clostridium difficile toxin: cytoskeletal changes and lactate dehydrogenase release in hepatocytes. J Surg Res. 2000;88(2):165-172. doi:10.1006/jsre.1999. 5736

31. Krijnen PA, Sipkens JA, Molling JW, et al. Inhibition of Rho-ROCK signaling induces apoptotic and non-apoptotic PS exposure in cardiomyocytes via inhibition of flippase. J Mol Cell Cardiol. 2010;49 (5):781-790. doi:10.1016/j.yjmcc.2010.07.017

32. Florin I. Isolation of a fibroblast mutant resistant to Clostridium difficile toxins A and B. Microb Pathog. 1991;11(5):337-346. doi:10.1016/0882-4010(91)90019-7

33. Solomon K, Webb J, Ali N, Robins RA, Mahida YR. Monocytes are highly sensitive to clostridium difficile toxin A-induced apoptotic and nonapoptotic cell death. Infect Immun. 2005;73(3):1625-1634. doi:10.1128/IAI.73.3.1625-1634.2005

34. Xia Y, Hu HZ, Liu S, Pothoulakis C, Wood JD. Clostridium difficile toxin A excites enteric neurones and suppresses sympathetic neurotransmission in the guinea pig. Gut. 2000;46(4):481-486. doi:10.11 36/gut.46.4.481

35. Farthing MJ. Enterotoxins and the enteric nervous system-a fatal attraction. Int J Med Microbiol. 2000;290(4-5):491-496. doi:10.10 16/S1438-4221(00)80073-9

36. Neunlist M, Barouk J, Michel K, et al. Toxin B of Clostridium difficile activates human VIP submucosal neurons, in part via an IL-1 $\beta$-dependent pathway. Am J Physiol Gastrointest Liver Physiol. 2003;285(5):G1049-G1055. doi:10.1152/ajpgi.00487.2002

37. Bassotti G, Macchioni L, Corazzi L, Marconi P, Fettucciari K. Clostridium difficile-related postinfectious IBS: a case of enteroglial microbiological stalking and/or the solution of a conundrum? Cell Mol Life Sci. 2018;75(7):1145-1149. doi:10.1007/s00018-0172736-1

38. Fettucciari K, Macchioni L, Davidescu M, et al. Clostridium difficile toxin B induces senescence in enteric glial cells: a potential new mechanism of Clostridium difficile pathogenesis. Biochim Biophys Acta Mol Cell Res. 2018;1865(12):1945-1958. doi:10.1016/j.bbamcr. 2018.10.007

39. Macchioni L, Davidescu M, Fettucciari K, et al. Enteric glial cells counteract Clostridium difficile Toxin B through a NADPH oxidase/ ROS/JNK/caspase-3 axis, without involving mitochondrial pathways. Sci Rep. 2017;7(1):45569. doi:10.1038/srep45569

40. Strasser A, O’Connor L, Dixit VM. Apoptosis signaling. Annu Rev Biochem. 2000;69(1):217-245. doi:10.1146/annurev.biochem.69.1. 217 
41. Kaufmann SH, Hengartner MO. Programmed cell death: alive and well in the new millennium. Trends Cell Biol. 2001;11(12):526-534. doi:10.1016/S0962-8924(01)02173-0

42. Mathiasen IS, Jaattela M. Triggering caspase-independent cell death to combat cancer. Trends Mol Med. 2002;8(5):212-220. doi:10.1016/ S1471-4914(02)02328-6

43. Jaattela M, Tschopp J. Caspase-independent cell death in T lymphocytes. Nat Immunol. 2003;4(5):416-423. doi:10.1038/ni0503-416

44. Johal SS, Solomon K, Dodson S, Borriello SP, Mahida YR. Differential effects of varying concentrations of Clostridium difficile toxin a on epithelial barrier function and expression of cytokines. $J$ Infect Dis. 2004;189(11):2110-2119. doi:10.1086/386287

45. El Feghaly RE, Bangar H, Haslam DB. The molecular basis of Clostridium difficile disease and host response. Curr Opin Gastroenterol. 2015;31(1):24-29. doi:10.1097/MOG.00000000000 00131

46. Solomon K, Martin AJ, O’Donoghue C, et al. Mortality in patients with Clostridium difficile infection correlates with host pro-inflammatory and humoral immune responses. J Med Microbiol. 2013;62(9):1453-1460. doi:10.1099/jmm.0.058479-0

47. Yu H, Chen K, Sun Y, et al. Cytokines are markers of the Clostridium difficile-induced inflammatory response and predict disease severity. Clin Vaccine Immunol. 2017;24(8):e00037-17. doi:10.1128/CVI.00 037-17

48. Czepiel J, Biesiada G, Brzozowski T, et al. The role of local and systemic cytokines in patients infected with Clostridium difficile. J Physiol Pharmacol. 2014;65(5):695-703.

49. Fachi JL, Felipe JS, Pral LP, et al. Butyrate protects mice from Clostridium difficile-induced colitis through an HIF-1-dependent mechanism. Cell Rep. 2019;27:750-761.e7.
50. Bassotti G, Marchegiani A, Marconi P, Fettucciari K. The cytotoxic synergy between Clostridioides difficile toxin $\mathrm{B}$ and proinflammatory cytokines: an unholy alliance favouring the onset of Clostridioides difficile infection and relapses. MicrobiologyOpen. 2020;8:e1061.

51. El Feghaly RE, Stauber JL, Deych E, Gonzalez C, Tarr PI, Haslam DB. Markers of intestinal inflammation, not bacterial burden, correlate with clinical outcomes in Clostridium difficile infection. Clin Infect Dis. 2013;56(12):1713-1721. doi:10.1093/cid/cit147

52. Li Y, Xu S, Xu Q, Chen Y. Clostridium difficile toxin B induces colonic inflammation through the TRIM46/DUSP1/MAPKs and NFкB signalling pathway. Artif Cells Nanomed Biotechnol. 2020;48 (1):452-462. doi:10.1080/21691401.2019.1709856

53. Sun X, Hirota SA. The roles of host and pathogen factors and the innate immune response in the pathogenesis of Clostridium difficile infection. Mol Immunol. 2015;63(2):193-202. doi:10.1016/j.molimm. 2014.09.005

54. He J, Lange J, Marinos G, et al. Advancing our functional understanding of host-microbiota interactions: a need for new types of studies. Bioessays. 2020;42:e1900211.

55. Oliva A, Aversano L, De Angelis M, et al. Persistent systemic microbial translocation, inflammation, and intestinal damage during Clostridioides difficile infection. Open Forum Infect Dis. 2019;7(1): ofz507. doi:10.1093/ofid/ofz507

56. Pirofski LA, Casadevall A. Antimicrobial therapy in the context of the damage-response framework: the prospect of optimizing therapy by reducing host damage. Antimicrob Agents Chemother. 2020;64(2): e01800-19. doi:10.1128/AAC.01800-19
Journal of Inflammation Research

\section{Publish your work in this journal}

The Journal of Inflammation Research is an international, peerreviewed open-access journal that welcomes laboratory and clinical findings on the molecular basis, cell biology and pharmacology of inflammation including original research, reviews, symposium reports, hypothesis formation and commentaries on: acute/chronic inflammation; mediators of inflammation; cellular processes; molecular mechanisms; pharmacology and novel anti-inflammatory drugs; clinical conditions involving inflammation. The manuscript management system is completely online and includes a very quick and fair peerreview system. Visit http://www.dovepress.com/testimonials.php to read real quotes from published authors. 